\title{
Olhar profissional para a docência com tecnologia: um estudo na formação continuada
}

Resumo: No artigo discutimos a competência do Olhar Profissional numa pesquisa com três professores de Matemática num curso de formação continuada com o objetivo de identificar a mobilização de conhecimentos pelo professor que indicam o desenvolvimento dessa competência para o ensino com tecnologia. A fundamentação veio do processo reflexivo docente na perspectiva da reflexão coletiva envolvendo vivências para a reconstituição das práticas e, quanto aos conhecimentos docentes para ensinar com Tecnologia, o apoio esteve no modelo TPACK. A metodologia foi qualitativa, do tipo estudo de caso, com coleta de dados feita por observação, entrevistas e recolha dos materiais produzidos nos encontros de formação, com análise interpretativa. Concluímos que no processo formativo desenvolvido houve mobilização de conhecimentos tecnológicos, pedagógicos e matemáticos, a qual foi percebida em um contexto de observação das tarefas envolvidas e das manifestações do raciocínio dos alunos, apontando possibilidades de ampliação do Olhar Profissional dos participantes.

Palavras-chave: Educação Matemática. Professores de Matemática. Tecnologias Digitais. Competência de Observar com Sentido.

\section{The professional noticing at the teaching with technology: a study in the continuing education}

Abstract: In the article we discussed the competence of

Professional Noticing in a research with three Mathematics teachers in a continuing education course with the aim of identifying the mobilization of knowledge by these teachers that indicate their development of the Professional Look competence for teaching with technology. The theoretical support came from the reflective teaching process, in the perspective of collective reflection involving experiences for the reconstitution of practices and, regarding the teaching knowledge to teach with technology, the support was in the TPACK model. The methodology was qualitative, of the case study type, with data collection made by observation, interviews and materials produced in the educational meetings, with interpretative analysis. We concluded that in the continuing educational process there was mobilization of technological, pedagogical, and mathematical knowledge, which was perceived in a context of observing the tasks involved and the manifestations of the students' reasoning, pointing out possibilities for expanding the participants' Professional Noticing. 
Keywords: Mathematics Education. Mathematics Teachers. Digital Technologies. Noticing with Sense.

\section{La mirada profesional a la enseñanza con tecnología: un estudio en la educación continua}

Resumen: En el artículo discutimos la competencia de la Mirada Profesional en una encuesta a tres profesores de Matemáticas en un curso de educación continua con el objetivo de identificar la movilización de conocimientos por parte del docente que indican el desarrollo de la competencia de Mirada Profesional para enseñar con tecnología. El razonamiento provino del proceso de enseñanza reflexiva en la perspectiva de la reflexión colectiva involucrando experiencias para la reconstitución de prácticas y, en cuanto a la enseñanza de conocimientos para enseñar con tecnología, el apoyo estuvo en el modelo TPACK. La metodología fue cualitativa, del tipo estudio de caso, con recolección de datos realizada por observación, entrevistas y recolección de materiales producidos en las reuniones de capacitación, con análisis interpretativo. Se concluye que en el proceso de formación desarrollado se produjo una movilización de conocimientos tecnológicos, pedagógicos y matemáticos, que se percibieron en un contexto de observación de las tareas involucradas y las manifestaciones del razonamiento de los estudiantes, señalando posibilidades de ampliación de la Mirada Profesional de los participantes.

Palabras clave: Educación Matemática. Profesores de Matemáticas. Tecnologías Digitales. Competencia para Observar con Sentido.

\section{Introdução}

A competência do professor de Matemática em identificar as características das situações de ensino e interpretá-las na perspectiva de tomar decisões sobre a condução da aula e do processo de ensino é vista, atualmente e cada vez mais, como um componente importante na prática didática (MASON, 2002). Para nós, formadores e pesquisadores no campo da educação continuada, é fundamental compreender como professores concebem o que é ensinar Matemática e como, no exercício da prática docente, são gerados conhecimentos docentes os quais, por sua vez, podem modificar a visão dos professores sobre o que é ensinar Matemática (HIEBERT, MORRIS e GLASS, 2003; LLINARES, 2011). Isso porque tal visão é fundada, entre outras questões, nas características do processo de construção do conhecimento docente necessário para ensinar Matemática.

Como consequência, algumas investigações têm se debruçado em identificar aspectos do uso de instrumentos como um meio para caracterizar práticas matemáticas na sala de aula. Para a análise do papel do professor na constituição das práticas que são geradas na sala de aula podemos nos perguntar: Como o professor usa a linguagem, os problemas e as diferentes maneiras de representação (sistemas simbólicos) entendidos 
como instrumentos na sua prática? Exemplos de estudos que se propõem a responder tais questões são aqueles focados no uso linguagem (ADLER, 1999) e nos modos de representação (LAMPERT, 1988).

Nessa perspectiva de identificar os conhecimentos matemáticos que impulsionam a competência do professor para um olhar profissional - em inglês, professional noticing - que lhe permita entrever o pensamento matemático do aluno, pesquisas têm se desenvolvido, tais como as de Llinares (2011, 2013, 2016). A ideia é investigar como auxiliar o professor a desenvolver esse olhar para o pensamento do seu aluno que lhe permita ver o raciocínio, ou seja, desenvolver o que Mason (2002) designou como olhar com sentido ou como observar profissionalmente para compreender o pensamento do outro.

Para tanto, partimos do pressuposto de que é fundamental, nas formações continuadas, discutir com os professores quais são os tipos de tarefas matemáticas e como implementá-las em sala de aula de modo a possibilitar essa mirada no raciocínio do aluno. $\mathrm{Na}$ pesquisa aqui relatada nos propusemos a investigar o olhar profissional docente no momento que a tecnologia está envolvida nas situações de aprendizagem com o objetivo de identificar a mobilização desses conhecimentos pelo professor, o que nos permite observar o desenvolvimento da competência do olhar profissional para o ensino com tecnologia.

Segundo definição de Llinares (2013), o olhar profissional é entendido como a capacidade de o professor identificar o que é relevante em uma situação no contexto de ensino para a aprendizagem matemática do aluno, interpretar a situação no contexto do ensino para fundamentar suas tomadas de decisão sobre as ações didáticas a serem empreendidas a partir dos objetivos estabelecidos. Partindo da ideia de que, ao ensinar, é o "conhecimento em uso" que permite ao professor gerar informações sobre situações de ensino, é possível identificar diferentes cenários nos quais o professor deve gerar informações para tomar decisões.

Vale destacar que, no ensino, a competência docente de "observar profissionalmente" as situações de aprendizagem têm se revelado complexa de ser desenvolvida, uma vez que ela exige do professor a mobilização de diferentes domínios do conhecimento em contextos nos quais ele deve tomar decisões e, muitas vezes, 
gerenciar dilemas de ensino, ou seja, tomar decisões entre duas ou mais situações contextuais conflitantes referentes ao desenvolvimento do ensino e da aprendizagem dos seus alunos. Esse dilema pode ser relativo à metodologia de ensino; aos objetivos a alcançar; ao conteúdo a ensinar; ao gerenciamento da classe e/ou à condução das tarefas matemáticas; à concepção de Matemática que o professor tem; e à sua formação também. (LLINARES, 2013; FORTUNY e RODRÍGUEZ, 2012; SÁNCHEZ-MATAMOROS, FERNANDEZ e LLINARES, 2015). Além disso, quando as situações de aprendizagem envolvem o uso de Tecnologia, a competência para observar profissionalmente abarca conhecimentos pedagógicos, tecnológicos e do conteúdo, tal como estão definidos no modelo intitulado Technological Pedagogical Content Knowledge — TPACK (MISHRA e KHOELER, 2006), conhecimentos estes ligados às características da Matemática em foco, dos recursos tecnológicos envolvidos e do contexto de ensino e de aprendizagem.

Em Llinares (2011) discute-se que o professor deve ser competente para planejar, organizar e conduzir a aprendizagem do aluno. É ele quem seleciona, organiza e implementa as ações didáticas e propicia formas de representação do conhecimento nas trajetórias de aprendizagem que elabora e conduz os alunos. autor É enfatizado, ainda, que os diferentes modos de representação do conhecimento escolhidos pelo professor ao ensinar estão postos em função de criar as condições para o aluno generalizar determinados mecanismos matemáticos e transformar uma representação em outra.

Nesta perspectiva, torna-se também necessário ao professor saber utilizar pedagogicamente os recursos tecnológicos compreendendo o seu potencial como mais uma forma de representação do conhecimento a ser explorado pelo aluno. Sob esse enfoque de uso integrado das tecnologias digitais da informação e comunicação (TDIC) ao currículo, as pesquisas de Almeida e Valente (2011) e de Lobo da Costa e Prado (2015) apontam que os recursos tecnológicos potencializam uma nova estrutura comunicacional, imprimindo maneiras diferentes de as pessoas se relacionarem, de se comunicarem e, também, de aprenderem

Nesse estudo consideramos a importância das novas tecnologias de forma que estas possam fazer parte do cotidiano de professores e alunos auxiliando-os a encontrar novos meios para estudar Matemática, tornando as aulas momentos privilegiados de interação com o conteúdo sendo pesquisado/estudado/aprendido pelos alunos por meio 
de diferentes fontes/ferramentas, incluindo a utilização de novas tecnologias. Assim, o aluno é um dos responsáveis pelo seu próprio desenvolvimento e o professor um mediador com a intencionalidade pedagógica para auxiliar os alunos na construção do conhecimento matemático envolvido.

Utilizar as TDIC na Educação demanda conhecimentos diversos os quais são necessários para que o professor de Matemática possa "raciocinar com", "criar com" e "ensinar com" a Tecnologia. Ensinar, não apenas inserindo-as na sala de aula, mas transformando a maneira de ensinar, integrando-as e explorando adequadamente o que elas potencializam para o ensino e a aprendizagem em Matemática, como apontam pesquisadores tais como Bittar, Guimarães e Vasconcelos (2008).

Este é um dos desafios que o professor enfrenta no cotidiano escolar: integrar a tecnologia ao currículo e desenvolver a competência de olhar com sentido para o aprendizado do aluno. Para tanto, o que está em jogo para o professor é o conhecimento tecnológico e pedagógico do conteúdo de Matemática e a competência do olhar profissional que, cada vez mais, é premente o professor desenvolver.

Entendemos que pesquisar em uma formação continuada como se dá a construção e mobilização de conhecimentos docentes quando se estuda e discute em conjunto o olhar profissional é relevante no sentido de contribuir tanto para a transformação da prática docente, quanto para o fornecimento de indicadores para a formação docente.

\section{Fundamentação Teórica e Objetivo}

A fundamentação teórica da pesquisa maior que subsidia este artigo foi formada por um tripé: a formação continuada, o desenvolvimento da competência do olhar profissional para a docência e os conhecimentos profissionais docentes necessários para ensinar com e na presença das tecnologias.

De acordo com Mason (2002), quando o professor de Matemática desenvolve o olhar profissional e está apto a olhar profissionalmente, ele consegue observar com sentido identificando, assim, de maneira profissional, situações dos processos de ensino e de aprendizagem e o comportamento do aluno ao desenvolvê-las, o que o distingue do modo de observar de alguém que não é professor de Matemática ou, ainda, de um outro 
professor que não tenha esse olhar.

O autor afirma, ainda, que uma característica do olhar profissional é a capacidade de o professor mobilizar seus conhecimentos para interpretar as situações de ensino e de aprendizagem na procura de uma forma estruturada e relevante para o entendimento dos processos matemáticos envolvidos. Para essa mobilização, existe uma relação de interdependência da compreensão de aspectos matemáticos e pedagógicos. A análise que o professor faz dos processos de ensino e de aprendizagem de Matemática está relacionada com sua formação acadêmica e com a prática pedagógica ao longo da vida caracterizando, assim, uma perspectiva interpretativa, ou seja, uma relação dialética entre o conhecimento teórico e o prático de quem mobiliza a competência do olhar profissional.

Em relação ao conceito de competência, assumimos, seja de forma explicita ou implícita, que não há competências sem conhecimento, no caso, sem conhecimento profissional docente, pois esse conhecimento é mais complexo do que a dicotomia tradicional entre conhecimento teórico e conhecimento prático; o conhecimento profissional é, ou pode ser, fundamento e resultado do exercício de competências, seja para os que se preparam para a profissão, seja para os profissionais já em exercício.

A formação continuada contribui para a formação acadêmica e prática do professor quando ela se desenvolve na perspectiva indicada por Imbernón (2006), qual seja, a de promover ações que propiciem preparar o professor na e para a mudança constante da sociedade e das demandas sociais para a Educação e, consequentemente, para os conhecimentos necessários à docência. Entendemos que, em uma formação que se proponha a subsidiar o professor para a integração de tecnologia na prática docente, é preciso criar espaços para a discussão e reflexão sobre o sentido da mudança e o papel da Tecnologia ao ensinar a Matemática. Isso para que os profissionais envolvidos possam socializar as experiências vivenciadas e se prepararem para enfrentar e conviver com as mudanças e as incertezas. Nesse enfoque, os estudos de Zeichner (1993) evidenciam que a formação, além de subsidiar as discussões, deve ter como foco tornar os professores reflexivos, críticos e autônomos para recriarem suas práticas, sendo a reflexão compartilhada fundamental nesse processo criativo. Na perspectiva da reflexão coletiva enfatizada por Zeichner (1993), a formação continuada deve envolver vivências para a reconstrução das práticas de sala de aula. 
A reflexão sobre a prática pode ser impulsionada na educação continuada por meio do compartilhamento das vivências e das experiências entre os pares e formadores. Entretanto, é fundamental que essas reflexões sejam alimentadas por estudos teóricos particularmente para viabilizar a compreensão e a reconstrução da própria prática. Sobre a prática reflexiva, pesquisas, tais como a de Kiill e Ribeiro (2020), têm constatado que a falta de apropriação teórica por meio do docente, sobre esta temática contribui para que o nível de reflexão esteja restrito a um âmbito puramente técnico, de modo que o professor identifica erros pontuais ou alguma atitude ou postura inadequada em sua mediação de sala de aula, sem se aperceber de aspectos mais estruturantes da própria prática.

Esse modelo teórico, que subsidiou a formação empreendida, criado por Mishra e Khoeler (2006), teve como ponto de partida estudos sobre a teoria da base do conhecimento profissional docente de Shulman (1986, 1987) que, nessa teoria, identificou um novo tipo de conhecimento denominado por ele de Conhecimento Pedagógico do Conteúdo, caracterizado como um novo conhecimento advindo de um amálgama entre o conhecimento do conteúdo e do conhecimento pedagógico.

A teoria desenvolvida por Shulman $(1986,1987)$ representa uma importante referência para os estudiosos da formação de professor e, nesse sentido, Lobo da Costa e Prado (2015) argumentam que vários pesquisadores, tais como Hughes (2004), Niess (2008) e Almeida e Valente (2011), retomaram tais ideias sobre o conhecimento do professor ampliando a discussão sobre a necessidade de incluir o conhecimento tecnológico para o ensino. Nesse caminho, Mishra e Koehler (2006) criaram o modelo TPACK, uma estrutura teórica para auxiliar na compreensão da natureza dos conhecimentos que são mobilizados pelos professores na docência. Essa estrutura é constituída pela integração de diferentes conhecimentos que resultam novos níveis de conhecimentos. Assim, como já foi dito anteriormente e retomando nas ideias de Shulman (1987), o Conhecimento Pedagógico do Conteúdo - em inglês Pedagogical Content Knowledge (PCK) - é um nível de conhecimento do professor que integra o conhecimento do conteúdo e o conhecimento das estratégias que possam ser mais adequadas para o ensino e favoreçam a compreensão do aluno sobre o tema em estudo.

O conhecimento de um determinado conteúdo, quando integrado ao conhecimento tecnológico, resulta no Conhecimento Tecnológico do Conteúdo - em inglês 
Technological Content Knowledge (TCK). Esse nível se expressa pela compreensão das relações recíprocas entre tecnologia e conteúdo. Para tanto, é necessário que os professores saibam, além do objeto da matéria que ensinam, em nosso caso a Matemática, a maneira pela qual sua abordagem muda com a aplicação da tecnologia.

O Conhecimento Pedagógico Tecnológico - do inglês Technological Pedagogical Knowledge (TPK) - é um nível de conhecimento integrado que envolve compreender quais as potencialidades e as implicações do uso das diferentes tecnologias nos processos de ensino e de aprendizagem. Envolve, por exemplo, saber quais aspectos cognitivos um aluno utiliza no processo de construir um vídeo. No contexto da educação, a identificação das potencialidades e restrições das tecnologias estão relacionadas às intencionalidades pedagógicas do professor.

Esses três tipos de domínios, os níveis PCK, TCK e TPK, quando se integram, na concepção de Mishra e Koehler (2006), dão origem ao Conhecimento Pedagógico Tecnológico do Conteúdo (Technological Pedagogical Content Knowledge - TPACK), uma forma emergente de conhecimento que simboliza uma mescla e que vai além de todos os seus componentes - conteúdo Matemática), Pedagogia e Tecnologia. É esse o tipo de conhecimento a ser mobilizado para ensinar com tecnologia e que o professor precisa desenvolver para exercer a docência, de modo que leve o aluno a pensar com Tecnologia e a construir seus conhecimentos.

Mishra e Koehler (2006) propuseram um referencial teórico para o uso da tecnologia educativa baseado na formulação de Shulman (1986), do PCK, designado de Conhecimento Pedagógico, Tecnológico do Conteúdo (originalmente TPCK, agora também conhecido como TPACK), que enfatiza as conexões que se estabelecem entre conteúdo, pedagogia e tecnologia, assim como a complexa interação entre esse conhecimento e o contexto. Um ensino que envolva recursos tecnológicos impõe a compreensão das relações de reforço mútuo entre estes elementos em conjunto, pois no centro do TPACK está a dinâmica entre conteúdo, pedagogia e tecnologia.

Este referencial teórico (Figura 1), para além de focar cada componente isoladamente, também foca nos pares: Conhecimento Pedagógico do Conteúdo (PCK), Conhecimento Tecnológico do Conteúdo (TCK), Conhecimento Tecnológico Pedagógico (TPK) e, também, os três em conjunto como gerando o conhecimento do 
Conteúdo Tecnológico Pedagógico (TPACK), pois “não há tal coisa como puro conteúdo, pura pedagogia ou pura tecnologia” (HARRIS, MISHRA e KOEHLER, 2009, p. 11).

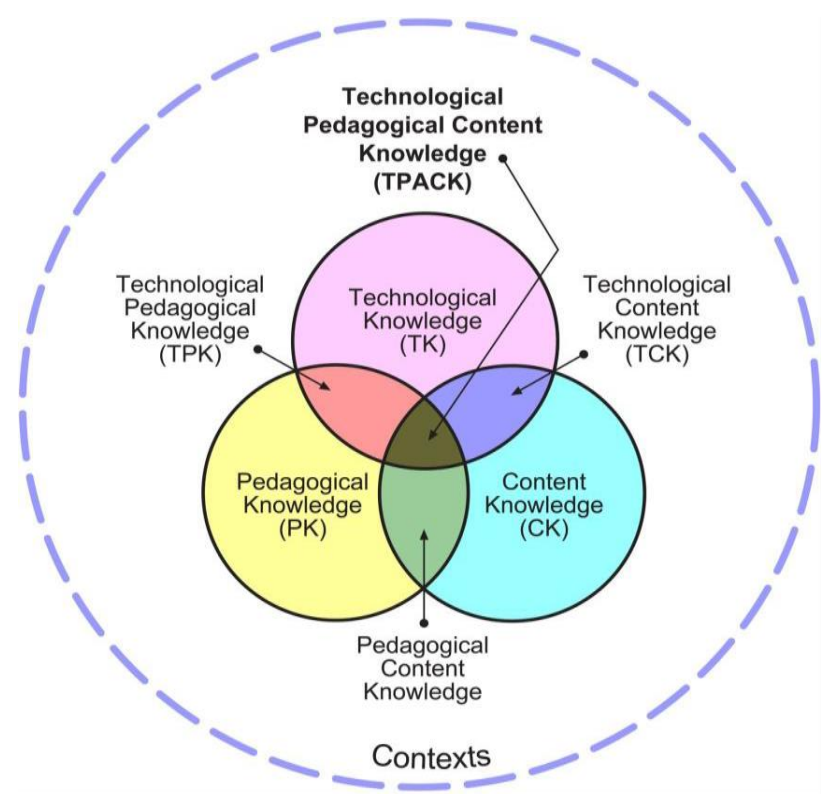

Figura 1: O quadro TPACK e os seus componentes do conhecimento (MISHRA e KOEHLER, 2009)

O TPACK é muito mais que estes três componentes isoladamente: conteúdo, pedagogia e tecnologia. Para ensinar eficazmente com tecnologia os professores precisam desenvolver uma concepção abrangente do assunto e o que significa ensinar com a tecnologia. Neste sentido, na docência, uma questão fundamental se relaciona à maneira pela qual o professor mobiliza seus conhecimentos para desenvolver a prática de ensinar. Para nós, pesquisadores em Educação, é preciso compreender a relação entre os diferentes componentes do conhecimento para o ensino que os professores devem ter para construírem ações educativas e resolverem situações problemáticas da sala de aula.

Vale ressaltar que esses conhecimentos são construídos em um determinado contexto que é determinante para eles. Desse modo, argumentamos que a capacidade do olhar profissional, que se vale dos conhecimentos do professor, é obviamente dependente do contexto.

A partir dessas considerações teóricas, a parte da pesquisa relatada neste artigo teve como objetivo identificar a mobilização de conhecimentos pelo professor que indicam o desenvolvimento da competência do olhar profissional para o ensino com tecnologia. 


\section{Metodologia}

A abordagem da pesquisa foi a qualitativa uma vez que, como explica Gamboa (2000), os propósitos fundamentais estiveram na compreensão, na explanação e na interpretação do fenômeno estudado. O investigador foi o instrumento principal no ambiente natural analisando os dados de forma indutiva e adotando estratégias e procedimentos de forma a considerar as experiências de acordo com o ponto de vista do sujeito da investigação, como indicam Bogdan e Biklen (1994). Para tais autores, em uma investigação qualitativa o ambiente natural é a fonte de dados; a palavra escrita assume particular importância para o registro de dados uma vez que esse tipo de pesquisa é a descritiva com análise indutiva; o processo é tão ou mais importante que os resultados encontrados e o significado é vital nesse tipo de pesquisa.

Segundo Yin (2001), quando queremos responder a questões relacionadas com o como e o porque de algum acontecimento ou situação complexa sobre os quais o pesquisador possui pouco ou nenhum controle, de modo que há dificuldade na identificação das variáveis consideradas importantes, a estratégia de investigação mais adequada é do tipo estudo de caso. Este se define com base nas características do fenômeno em estudo e com base em um conjunto de características associadas ao processo de recolha de dados e às estratégias de análise. Assim sendo, esta investigação foi qualitativa, do tipo estudo de caso.

$\mathrm{Na}$ pesquisa maior ${ }^{1}$ que embasa este artigo foi proposto um caminho metodológico em etapas e os sujeitos foram professores de Matemática participantes de um projeto de extensão de uma universidade pública em Mato Grosso do Sul, em um processo de formação continuada. A formação dos professores ocorreu durante um ano e meio, com encontros semanais de duas horas e teve a finalidade de explorar as diferentes fases (compreensão, exploração/descoberta, justificação/validação) para os participantes desenvolverem competências e habilidades docentes, entre elas a do olhar profissional.

A primeira etapa desta pesquisa maior foi a da experiência piloto com a observação da prática docente de um professor de Matemática com filmagens a serem usadas no processo formativo e a segunda etapa foi a do processo formativo propriamente

1 Olhar profissionalmente para a Docência com tecnologia na formação continuada. CAAE:15429919.5.0000.8030; número do Parecer:3.690.905 
dito, no qual a coleta de dados foi feita por entrevistas, recolha dos materiais produzidos nos encontros e observação participante, com análise interpretativa.

Neste artigo discutimos um recorte da pesquisa que versou sobre estudo de figuras planas e suas características como área, perímetro, ângulo etc. Foi utilizado o software GeoGebra explorando a linguagem analítica e a geométrica.

Optamos pelo uso do GeoGebra por ser uma ferramenta livre, disponível em todas as plataformas para dinamizar as aulas, disponibilizando recursos diferenciados para as aulas de Matemática. Esse software de Geometria dinâmica é utilizado em vários campos da Matemática permitindo diversas possibilidades de interação e, consequentemente, a produção individual e coletiva. Entretanto, vale salientar que não existe uma solução tecnológica milagrosa e única que se aplica a todos os professores, alunos, cursos, tópicos.

Na sequência, apresentamos a experiência piloto cuja filmagem foi assistida e discutida pelos professores participantes do projeto de formação continuada. Cabe destacar que a preparação para a prática profissional envolve não apenas aprender o conhecimento pertinente ao domínio da prática mas, também, desenvolver uma visão profissional (GOODWIN, 1994 apud ROONEY e BOUD, 2019, p. 444). Ou seja, construir uma forma de observar e compreender eventos que são responsáveis aos interesses distintos de um determinado grupo social. Os professores desenvolvem a capacidade de entender o que observam em sua prática diária e usam sua compreensão do que está sendo observado para tomar decisões sobre como agir na docência.

Embora a atividade cognitiva esteja envolvida, como explicitou Goodwin (1994) apud Rooney e Boud (2019), a função sensorial humana de ver fornece um ponto de partida inicial. No entanto, para Goodwin, assim como para nós, é uma forma diferenciada de ver o que está em jogo, trata-se da forma que só o profissional tem de ver a situação.

\subsection{O piloto}

$\mathrm{Na}$ experiência piloto acompanhamos e observamos a atuação didática de um professor de Matemática da Educação Básica que atua em uma escola pública de Mato Grosso do Sul, situada em uma região do interior do Estado, aqui referido por Professor $\pi$. A sequência de tarefas matemáticas elaborada pelo professor foi planejada para abordar 
o conceito de polígono iniciando o estudo de figuras planas, tais como triângulos, quadrados, losangos e retângulos, de modo a levar o aluno a conhecer a forma e as propriedades de cada uma delas como aqueles que possuem todos os lados com o mesmo comprimento e todos os ângulos com a mesma medida, ângulos, vértices, diagonais e lados. O desenho para um ambiente de aprendizagem com a tecnologia foi elaborado a partir do material curricular de Matemática Projeto Telaris, referente do $6^{\circ}$ ao $9^{\circ}$ ano do Ensino Fundamental, que é o livro didático adotado na rede de ensino do Estado, e contemplou discussões com 18 alunos do $7^{\circ}$ ano em aula regular, durante duas aulas de 50 minutos cada, sobre o conteúdo de polígonos e a exploração desses com o uso do software GeoGebra (LOBO DA COSTA e FIGUEIREDO, 2018).

Nesta fase da pesquisa coube a nós, como formadores, identificar quais foram as intervenções didáticas do Professor $\pi$ feitas na tentativa de auxiliar os alunos a aprender, partindo do que o referido professor antevia sobre o pensamento dos alunos durante a realização da atividade. A partir da observação como formadores procuramos evidenciar as argumentações do Professor $\pi$ para levar os alunos a perceberem equívocos e acertos na estratégia da construção geométrica, ou seja, o pensamento matemático do aluno (LLINARES, 2011).

O que destacamos nesta fase foi a constatação de que observando a prática profissional de professores pode-se perceber características particulares que levam a novos aprendizados tais como: identificar os aspectos relevantes da situação de aprendizagem; interpretar o conhecimento sobre o contexto para pensar sobre as interações possíveis em sala de aula; acompanhar as tomadas de decisões e as ações do docente. Tais características ocorreram na investigação, porém, isso não quer dizer que a aprendizagem profissional ocorra sempre automaticamente quando se observa episódios da prática profissional de um outro professor. Entretanto, esta observação pode levar o professor a reconhecer os aspectos que podem ser relevantes na sala de aula para auxiliar a aprendizagem da Matemática.

Uma intervenção didática que evidenciou o olhar com sentido ocorreu em uma das tarefas que foi a construção de polígonos. O Professor $\pi$ propôs aos alunos a construção de um quadrado no GeoGebra e, para a sua resolução, foi desabilitada a ferramenta polígono do software, ou seja, a construção deveria ser feita por meio do uso 
de ferramentas do software, tais como circunferência, compasso, retas paralelas, retas perpendiculares, reflexão, translação etc. Para a verificação do resultado, os alunos foram orientados a medir os ângulos internos da figura construída e a movimentarem, observando o que ocorria com esses ângulos internos durante o movimento — atividade esta possibilitada por se tratar de um software dinâmico. Ao realizar essa atividade, um dos alunos constatou que a construção feita por ele não poderia ser considerada como um quadrado, embora tivesse se proposto a construir um quadrado. O Professor $\pi$ perguntou ao aluno como foi que chegou a essa conclusão. A resposta foi que, ao movimentar a figura, ele percebeu que os ângulos internos não mediam sempre $90^{\circ} \mathrm{e}$, assim sendo, a figura não contemplava uma das propriedades do quadrado, que é a de ter todos os ângulos internos medindo $90^{\circ}$, como discutido em sala anteriormente.

A partir desse diálogo, o Professor $\pi$ interveio argumentando sobre como poderia ser feita uma construção no GeoGebra de modo que, ao movimentar os vértices, os ângulos internos fossem sempre retos; isso na tentativa de levar o aluno a raciocinar sobre alguma das possibilidades de procedimentos corretos necessários para a construção da figura poligonal solicitada. No caso, a proposta foi a construção de retas paralelas e retas perpendiculares para definir ângulo de $90^{\circ}$. Em seguida, o Professor $\pi$ questionou o aluno perguntando: Será que se os ângulos fossem todos de $90^{\circ}$ já poderíamos concluir que se trata de um quadrado?

Observamos que o Professor $\pi$ procurou dialogar com o aluno partindo do seu raciocínio, mas levando-o além, ou seja, para a conclusão de que a figura não poderia ser considerada um quadrado possuindo apenas os ângulos internos medindo $90^{\circ}$, isso é necessário, mas não suficiente. Como destacado em Llinares (2009), existem situações na sala de aula nas quais os alunos podem gerar respostas para tarefas desafiadoras que não correspondem a procedimentos padronizados. Essas respostas são janelas à compreensão do raciocínio deles que podem proporcionar informações relevantes sobre a maneira como estão aprendendo; é neste momento que caracterizamos, ou não, o olhar profissional.

Chamamos a atenção para a postura do Professor $\pi$ quanto ao domínio do conhecimento do conteúdo matemático, do pedagógico e do tecnológico de forma a mediar a aprendizagem do aluno com o uso do GeoGebra, um software (tecnologia) cujo 
entorno é em prol da construção do conhecimento do aluno, como apontam Mishra e Koehler (2009).

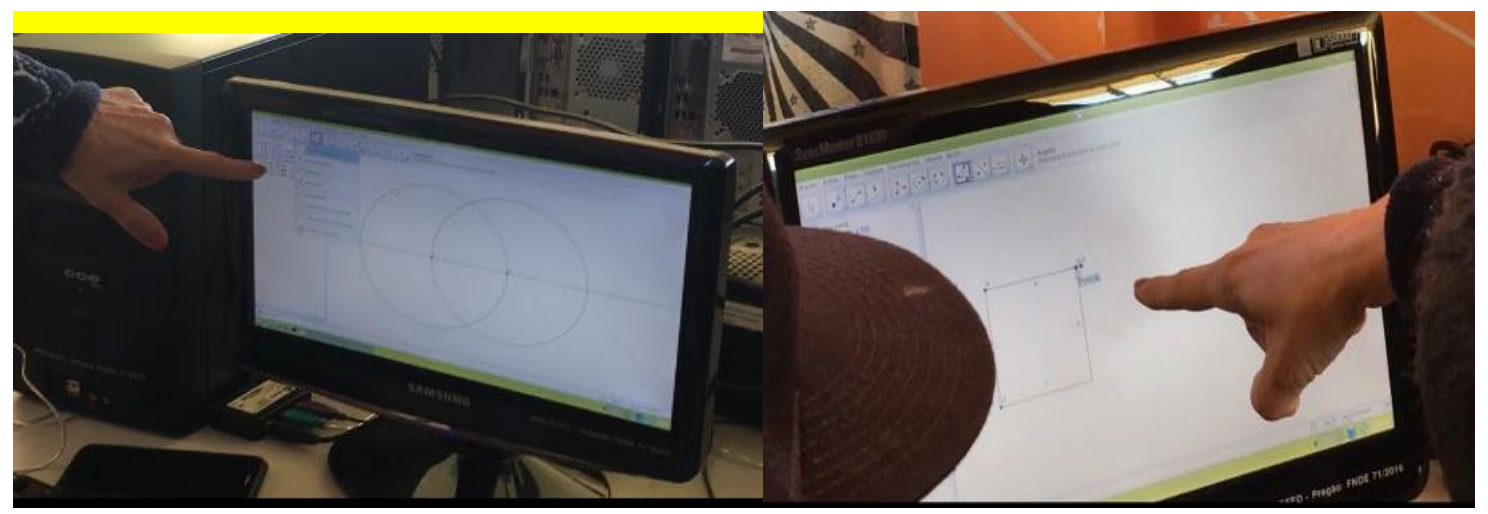

Figura 2: Na esquerda (A) a construção do polígono e na direita (B) a medida dos ângulos internos (Dados da Pesquisa)

Na Figura 2, em A, com as filmagens feitas, capturamos o exato momento em que o Professor $\pi$ apontou para o aluno e argumentou sobre propriedades para a construção do polígono solicitado. No caso, o aluno construiu circunferências de mesmo raio para dar início à construção do quadrado. Na Figura 2, em B, observamos o Professor $\pi$ apontando a medida do ângulo calculado, dialogando e explicando o porquê de a figura anteriormente construída não ser um quadrado, apenas com essa propriedade (de ter ângulos internos de $90^{\circ}$ ), embora na tela parecesse um quadrado.

Considerando que um quadrado é um polígono de quatro lados congruentes, com todos os ângulos internos de 90 graus e com diagonais congruentes perpendiculares e que se cruzam no ponto médio, uma das formas de construção do quadrado é a de obter dois segmentos que se cortem perpendicularmente no ponto médio. Dessa forma, as extremidades do segmento são os vértices do quadrado que queremos construir.

Observamos as ações do Professor $\pi$ ao identificar as estratégias de resolução de um determinado aluno e ao mesmo tempo interpretar as produções e orientar os processos de resolução (gestão do professor) e, ainda, em relacionar entre si a forma sistêmica a partir dos elementos acima, justificá-los desde a teoria para explicar as situações reais de ensino.

Nesta configuração destacamos a mobilização por parte do professor do conhecimento tecnológico do conteúdo Matemático, no caso, figuras planas e o software GeoGebra. Além disso, por ser capaz de usar essa tecnologia para ensinar o conteúdo 
matemático houve a mobilização do conhecimento pedagógico-tecnológico para lecionar tornando o conteúdo compreensível e acessível aos alunos, organizando e gerindo a aula.

Neste sentido, destacamos que o conhecimento profissional docente necessário para ensinar Matemática é multidimensional e integra o conhecimento sobre a Matemática, sobre os alunos e sobre o ensino em contextos institucionais, vinculado ao sistema de tarefas e sequências didáticas que configuram a prática do ensinar Matemática.

Em complemento, em Llinares (2009) evidencia-se que a organização do conteúdo para ensinar implica em conhecer os conteúdos matemáticos como objeto de ensino e de aprendizagem utilizando a informação desses conteúdos para planejar, selecionar e analisar tarefas matemáticas como instrumentos para aprendizagem classificando essas tarefas de acordo com a demanda cognitiva de cada uma delas. Também, é necessário utilizar esse conhecimento para planejar, selecionar, analisar e modificar sequências de ensino previamente estabelecidas.

Considerando que as tarefas matemáticas podem determinar o que os alunos conseguem aprender, elas são instrumentos para o professor utilizar de modo que os alunos aprendam Matemática.

Analisamos que, no experimento, houve um vínculo entre a aprendizagem e a gestão ou gerenciamento das tarefas em sala de aula com o recurso do GeoGebra. De acordo com o referencial teórico, destacamos que não é só a tarefa que condicionará a aprendizagem dos alunos, mas o que eles farão com ela e como o professor a conduz, ou seja, a forma emergente de conhecimento simbolizado em uma mescla de conteúdo (a Matemática), pedagogia e tecnologia.

A experiência piloto foi feita e gravada para ser utilizada na e para o design do curso de formação continuada relatada na sequência do texto.

\subsection{A pesquisa no curso de formação continuada}

Os participantes foram três professores de Matemática, denominados aqui por Professor A, Professor B e Professor C, os quais participaram de um curso de educação continuada com recurso tecnológico, em específico o software GeoGebra, em Nova Andradina, Mato Grosso do Sul. Os professores participantes foram entrevistados e todos 
declararam utilizar tecnologia ao ensinar Matemática e se consideravam habilitados ao uso da tecnologia em sala de aula. Salientamos que a entrevista ocorreu antes de assistirem à gravação do projeto piloto que versou sobre estudos de figuras planas e suas características explorando a linguagem analítica e a geométrica.

Por exemplo, o Professor A — que é formado há nove anos e leciona desde então as disciplinas de Matemática, Física, Química e Informática — quando perguntado como considera a integração da tecnologia ao currículo escolar, respondeu: “Não só considero, como vejo que é indispensável. Hoje se você for dar uma aula de Matemática usando só aquelas ferramentas da antiguidade, só giz e lousa, você fica travado, principalmente nas disciplinas de exatas. [...] hoje, é indispensável que você traga algo que prenda a atenção dos jovens. Porque eles já estão inseridos na era digital, por que eu vou me recusar a viver nela? Não tem como hoje, preparar uma aula sem usar um recurso tecnológico".

Destacamos o olhar crítico do Professor A explicitando a necessidade de escolhas de recursos tecnológicos a serem usados em sala de aula, o que requer compreensão das complexas relações entre pedagogia, conteúdo e tecnologia, permitindo uma construção de estratégias específicas ao contexto. Assim, notamos que o Professor A enfatizou a importância do uso da tecnologia para motivação do aluno não tendo citado na sua fala no que a tecnologia contribui para a aprendizagem, ou quais são as possibilidades diferentes do uso da tecnologia para o ensino do que as viabilizadas pelo "giz e lousa".

O curso de formação teve duas partes: uma de formação mais técnica sobre o software GeoGebra e outra mais teórica centrada em estudos sobre o conceito de olhar profissional. A fase técnica consistiu no aprendizado e na utilização do GeoGebra envolvendo desde a exploração das ferramentas, inclusive as ligadas à translação, rotação e simetria axial, até construções diversas e exploração da janela de álgebra. Na fase dedicada ao conceito de olhar profissional, além dos estudos teóricos, procurou-se relacionar a teoria com a prática e a ideia foi a de pensar no ensino de Matemática como um contexto em que os professores fossem capazes de observar e analisar uma situação de ensino e aprendizagem, de forma a identificar elementos que fossem relevantes para ela para explicar o que pode estar sucedendo com os alunos e, a partir disso, tomar decisões de ações adequadas para ajudar a aprendizagem Matemática dos estudantes. 
Assim, no curso de formação continuada, os Professores A, B e C iniciaram assistindo ao vídeo da experiência piloto juntamente com o Professor $\pi$, que foi convidado a participar desta seção.

Na sequência, como formadores, dialogamos com os professores de modo que eles fossem discutindo o que assistiram e, sobretudo, analisassem o processo de planejamento realizado no GeoGebra. Como o Professor $\pi$ estava presente, explicou que seu objetivo quando interveio argumentando sobre a construção do quadrado foi o de ajudar o aluno a perceber os defeitos em sua construção geométrica.

O Professor B declarou: "Na visualização, ele vai conseguir ver bem e conseguir girar a figura. Aí o Professor $\pi$ poderá explicar tudo para ele, o que é vértice, aresta e lado do quadrado".

O Professor $\pi$ complementou ainda o seu raciocínio dizendo que "por mais que você faça a figura na lousa, o aluno não consegue enxergar as vistas e no software GeoGebra é possível movimentar a figura".

Com base nas falas, destacamos uma potencialidade do software que é a de auxiliar a visualização que o aluno terá com a figura em movimento, de modo a identificar invariantes. Por meio da Janela de Visualização do GeoGebra é possível explorar conceitos que ainda não são conhecidos pelos alunos, inclusive todo o processo de construção da figura plana e conjecturar possíveis entendimentos com base nas simulações de tarefas matemáticas que podem ser feitas com o uso do software.

Vale destacar que, quanto ao Professor $\pi$, houve mobilização de Conhecimento Tecnológico do Conteúdo ao preparar sua aula prática, inclusive utilizando a ferramenta para ir além da proposta inicial de sua aula e comparar os dois momentos, antes e após seu estudo, participando do curso de formação apresentando, deste modo, uma evolução do conhecimento tecnológico-pedagógico da própria aprendizagem no curso de formação. O conhecimento tecnológico surge do uso do GeoGebra nesta atividade desenvolvida pelo Professor $\pi$; além disso, ao considerarmos o uso deste instrumento para elaborar uma aula em que a tecnologia foi utilizada pedagogicamente para o ensino de um conteúdo temos presente e em uso os conhecimentos abrangidos pelo TPACK.

A Figura 3 ilustra o momento da manipulação da figura geométrica pelo aluno preservando as suas propriedades, indicando que, para a construção no GeoGebra, o aluno 
se utilizou de propriedades tais como: retas perpendiculares, retas paralelas, ferramenta compasso, entre outras. A aula abordou o ensino não só das ferramentas disponíveis no manuseio do software como propriedades fundamentais da geometria plana na construção do polígono.

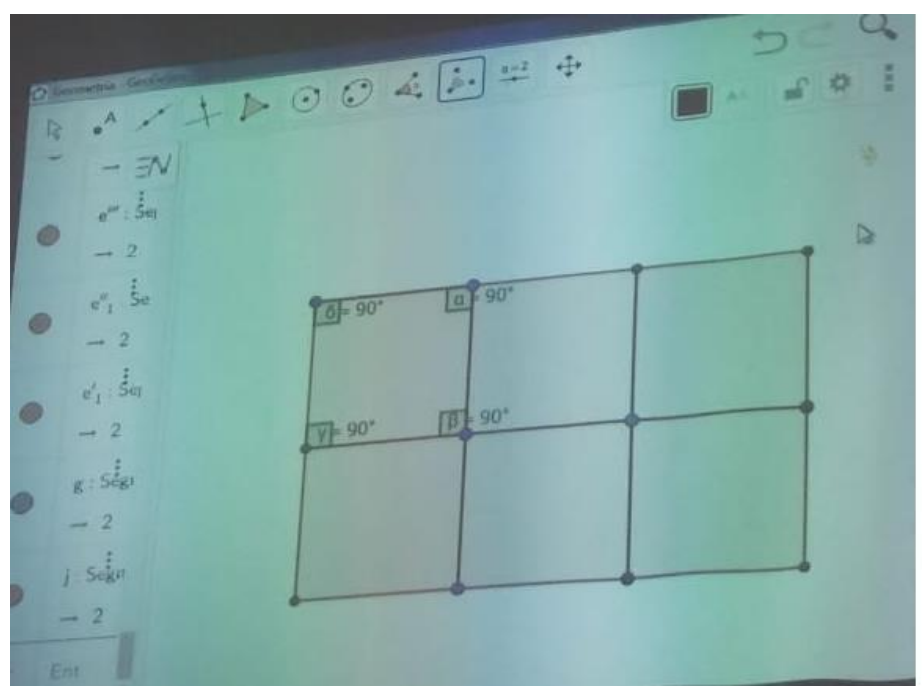

Figura 3: Manipulação da figura Geométrica (Dados da Pesquisa)

No curso, sobre o vídeo assistido, perguntamos aos participantes como eles comparavam o uso de software para o ensino de Matemática com outros recursos pedagógicos já utilizados. O Professor C respondeu: “Evidenciamos que o Professor $\pi$ realizou a experimentação com GeoGebra ao iniciar a tarefa com os alunos e, a partir da exploração das ferramentas do software, [o aluno] produziu conhecimento nessa interação com o GeoGebra, tendo sucesso na produção da atividade". Em seguida completou ao Professor A: "A atividade do Professor $\pi$ atendeu o seu propósito, de forma que um dos alunos construiu a figura e, ao mexer um dos pontos da construção, o quadrilátero deixou de ser quadrado e passou a ser um retângulo". Completou então o Professor B: “A construção não foi feita a partir da definição do objeto matemático, assim observamos um grande potencial para o ensino na opção do Professor $\pi$ de utilizar o software GeoGebra como recurso pedagógico".

No diálogo entre os participantes foi bastante citado o problema da falta de domínio do GeoGebra por parte dos estudantes extrapolando a questão conceitual. Desta forma, observaram que o Professor $\pi$ precisou planejar, além da construção e exploração conceitual das figuras, o ensino do uso das ferramentas e das funções do software com a finalidade de o aluno dominar os comandos básicos e, assim, poder escolher e manipular 
bem as possibilidades viabilizadas pelo software para contemplar as características presentes na construção das figuras planas em questão.

Esta discussão evidenciou a importância do Conhecimento PedagógicoTecnológico (TPK), que é o tipo de conhecimento que capacita o professor para utilizar determinadas tecnologias para o ensino e a aprendizagem, integrando a tecnologia com estratégias pedagógicas gerais. De acordo com Mishra e Koehler (2006, p. 1028), "é o conhecimento da existência de diversos componentes e recursos tecnológicos e como eles podem ser utilizados no cenário de ensino e aprendizagem”. Assim, o TPK refere-se à capacidade de utilizar criticamente os recursos tecnológicos em um contexto pedagógico.

\section{Considerações finais}

Os dados analisados nos permitiram concluir que as discussões empreendidas ao longo do processo de formação continuada favoreceram reflexões dos participantes relacionadas: às decisões didáticas do Professor $\pi$; ao uso do software na aula de Matemática para a resolução do problema; a trajetória de aprendizagem planejada pelo professor; aos conhecimentos matemáticos em jogo e às possibilidades de aprendizagem para os alunos. Assim, entendemos que houve a oportunidade de construir/mobilizar conhecimentos pelos participantes do processo de formação continuada, especialmente sobre a seleção e uso pedagógico da tecnologia para o ensino. Os participantes perceberam, por meio da vivência ao longo da experimentação, os limites e possibilidades do uso pedagógico do GeoGebra que foi um recurso ou ferramenta pedagógica que pode potencializar a aprendizagem dos alunos sobre polígonos. Os Professores apresentaram, em diversos momentos, os conhecimentos integrantes do TPACK e, a partir dessa compreensão teórica, acompanhar um professor em sala de aula, em um Estudo Piloto, para observação da prática pedagógica e da competência do olhar profissional em ação em uma situação real de ensino.

Na formação continuada dos três professores, cabe destacar que, ao assistirem ao vídeo do projeto piloto, eles externaram a necessidade de acesso a mais observações de sala de aula para desenvolver o olhar profissional e de participação em discussões conjuntas tanto sobre esse conceito, quanto sobre a prática observada. Assim, concluímos que a formação continuada desenvolvida com os professores-participantes foi relevante 
para ampliar e auxiliar na mobilização de conhecimentos, empreender estudos conjuntos sobre o conceito de olhar profissional, assistir aos vídeos da prática de um docente e analisá-la em conjunto.

Consideramos ser necessário analisar situações de ensino para inferir sobre a mobilização de conhecimentos que indicam o desenvolvimento da competência do professor para o olhar profissional e as maneiras mais pertinentes de utilizá-la para tomar as melhores decisões. Logo, é importante que aconteçam experiências desse tipo e, além disso, que se tenha nos processos formativos a oportunidade de dialogar com o docente observado de modo a perceber seu ponto de vista sobre a situação real de ensino e a importância do ver o raciocínio do aluno e perceber o que é adequado para a aprendizagem no momento de tomar as decisões. O desenvolvimento dessa percepção implica uma pedagogia a ser praticada e seus efeitos refletidos.

Conhecimentos tecnológicos por si só não permitem aos professores o desenvolvimento e mobilização da competência de olhar profissional, pois é preciso saber usar a tecnologia pedagogicamente e estabelecer relações dinâmicas com o conteúdo para auxiliar a aprendizagem dos alunos. Ressaltamos que aprender sobre a tecnologia é diferente de aprender o que fazer com ela educacionalmente. Sugerimos que a pedagogia da observação seja desenvolvida por meio de estudos em cursos presenciais e como eles podem não apenas buscar resultados de aprendizagem sobre o conceito matemático.

Assim, as representações muitas vezes fornecem um tipo de modelo de pensamento dos estudantes de forma que a aprendizagem é evidenciada no processo de apropriação de um modo de pensar e usar as ferramentas da prática. Os resultados nos proporcionaram descritores da competência docente de olhar profissionalmente $o$ pensamento dos estudantes no contexto da generalização e apontaram informações para o desenho de intervenções na formação de professores que tenham como um de seus objetivos se apoiar no reconhecimento das evidências da compreensão Matemática dos estudantes.

Concluímos que na formação continuada desenvolvida com os professoresparticipantes, foi relevante para ampliar conhecimentos empreender estudos conjuntos sobre o conceito de olhar profissional, assistir aos vídeos da prática de um docente e os analisar em conjunto, além disso, ter a oportunidade de dialogar com esse docente 
Em síntese, concluímos que no processo formativo desenvolvido houve mobilização de conhecimentos tecnológicos, pedagógicos e matemáticos, os quais foram percebidos em um contexto de observação das tarefas envolvidas e das manifestações do raciocínio matemático dos alunos.

A partir dessas discussões e análises o estudo continuará com a elaboração, organização e aplicação de tarefas em sala de aula que serão registradas novamente em vídeo e, posteriormente, analisadas em conjunto. A atuação em sala de aula será objeto de discussão e análise para subsidiar o desenvolvimento da competência do olhar profissional dos participantes da formação. As ações realizadas na formação continuada poderão gerar a implementação de intervenções pedagógicas nas escolas envolvidas no processo, com ações educativas inovadoras já discutidas e analisadas durante o processo da formação.

\section{Referências}

ADLER, Jill. A language of teaching dilemmas: unlocking the complex multilingual secondary mathematics classroom. For the Learning of Mathematics, v. 18, n. 1, p. 2433, jan./apr. 1998.

ALMEIDA, Maria Elizabeth Bianconcini; VALENTE, José Armando. Tecnologias e Currículo: trajetórias convergentes ou divergentes? São Paulo: Paulus, 2011.

BITTAR, Marilena; GUIMARÃES, Sheila Denize; VASCONCELLOS Mônica. A integração da tecnologia na prática do professor que ensina Matemática na Educação Básica: uma proposta de pesquisa-ação. Revemat, Florianópolis, v. 3, n. 1, p. 84-94, 2008.

BOGDAN, Robert; BIKLEN, Sari Knopp. Investigação qualitativa em Educação: uma introdução à teoria e aos métodos. Tradução de Maria João Alvez, Sara Bahia dos Santos, Telmo Mourinho Baptista. Porto: Porto, 1994.

FORTUNY, Josep. M.; RODRÍGUEZ, R. Aprender a mirar con sentido: facilitar la interpretación de las interacciones en el aula. Avances de Investigación en Educación Matemática, Granada, v. 1, n. 1, p. 23-37, ene./jun. 2012.

GAMBOA Silvio Sanchez. Tendências epistemológicas: dos tecnicismos e outros "ismos" aos paradigmas científicos. In: SANTOS FILHO, José Camilo; GAMBOA, Silvio Sanchez (Org). Pesquisa Educacional: quantidade-qualidade. São Paulo: Cortez, 2000, p. 60-83.

HARRIS, Judith; MISHRA, Punyahloke; KOEHLER, Matthey J. Teachers' technological pedagogical content knowledge and learning activity types: curriculumbased technology integration reframed. Journal of Research on Technology in Education, 
v. 41, n. 4, p. 393-416, 2009.

HIEBERT, James; MORRIS, Anne K.; GLASS, Brad. Learning to learn to teach: an "experiment" model for teaching and teacher preparation in Mathematics. Journal of Mathematics Teacher Education, n. 6, p. 201-222, sep. 2003.

HUGHES, Joan. Technology learning principles for preservice and in-service teacher education. Contemporary Issues in Technology and Teacher Education, Waynesville, v. 4, n. 3, p. 345-362, 2004.

IMBERNÓN, Francisco. Formação docente e profissional: formar-se para a mudança e a incerteza. Tradução de Silvana Cobucci Leite. São Paulo: Cortez, 2006.

KIILL, Ayrton Araújo; RIBEIRO, Rogério Marques. A reflexão sobre a prática e o discurso de professores: um estudo de caso. Educação Matemática Debate, Montes Claros, v. 4, n. 10, p. 1-15, 2020.

LAMPERT, Magdalene. What can research on teacher education tell us about improving quality in Mathematics Education? Teaching and Teacher Education, v. 4, n. 2, p. 157$170,1988$.

LLINARES, Salvador. ¿Cómo dar sentido a las situaciones de enseñanza-aprendizaje de las Matemáticas? Algunos aspectos de la competencia docente del profesor. Cuadernos de Investigación y Formación en Educación Matemática, Costa Rica, v. 11, n. 15, p. 5767, jun. 2016.

LLINARES, Salvador. Competencias docentes del maestro en la docencia en Matemáticas y el diseño de programas de formación. Uno - Revista de Didáctica de las Matemáticas, Barcelona, n. 51, p. 92-101, abr. 2009.

LLINARES, Salvador. Formación de profesores de Matemáticas: caracterización y desarrollo de competencias docentes. In: CONFERENCIA INTERAMERICANA DE EDUCACIÓN MATEMATICA, 13, 2011, Recife. Actas del XIII CIAEM. Recife: IACME/UFPE, 2011, p. 1-9.

LLINARES, Salvador. Professional Noticing: a component of the Mathematics teachers' professional practice. Sisyphus, Lisboa, v. 1, n. 3, p. 76-93, jan./abr. 2013.

LOBO DA COSTA, Nielce Meneguelo; FIGUEIREDO, Sonner Arfux de. A competência de "olhar profissionalmente" o ensino da Matemática em um entorno Tecnológico: algumas características. In: SEMINÁRIO SUL-MATO-GROSSENSE DE PESQUISA EM EDUCAÇÃO MATEMÁTICA, 12, 2018, Campo Grande. Anais do XII SESEMAT. Campo Grande: UFMS, 2018, p. 119-131.

LOBO DA COSTA, Nielce Meneguelo; PRADO, Maria Elisabette Brisola Brito. A integração das tecnologias digitais ao ensino de Matemática: desafio constante no cotidiano escolar do professor. Perspectivas da Educucação Matemática, Campo Grande, v. 8, n.16, p. 99-120, jan./abr. 2015.

MASON, Jennifer. Qualitative researching. 2ed. Ed. London: Sage Publications, 2002. 
MISHRA, Punya; KOEHLER, Matthey J. Technological Pedagogical Content Knowledge: a new framework for teacher knowledge. Teachers College Record, v. 108, n. 6, p. 1017-1054, 2006.

NIESS, Margaret. Mathematics Teachers Developing Technology, Pedagogy and Content Knowledge (TPACK). In: INTERNATIONAL CONFERENCE SOCIETY FOR INFORMATION TECHNOLOGY \& TEACHER EDUCATION, 2008, Las Vegas. Proceedings of SITE. Waynesville: AACE, 2008, p. 5297-5304.

ROONEY, Donna; BOUD, David. Toward a pedagogy for professional noticing: Learning through observation. Vocations and Learning, v. 12, n. 3, p. 441-457, 2019.

SÁNCHEZ-MATAMOROS, Glória; FERNÁNDEZ, Ceneida; LLINARES, Salvador. Developing pre-service teachers' noticing students' understanding of the derivative concept. International Journal of Science and Mathematics Education, n. 13, p. 13051329, dec. 2015.

SHULMAN, L. S. Knowledge and teaching: foundations of the new reform. Harvard Educational Review, Cambridge, v. 57, n. 1, p. 1-23, feb. 1987.

SHULMAN, Lee S. Those who understand: knowledge growth in teaching. Educational Researcher, Washington, v. 15, n. 2. p. 4-14, feb. 1986.

YIN, Robert. K. Estudo de caso: planejamento e métodos. Tradução de Ana Thorell. Porto Alegre: Boookman, 2001.

ZEICHNER, Kenneth M. A formação reflexiva de professores: ideias e práticas. Tradução de Afonso José Carmona Teixeira, Maria João Carvalho, Maria Nóvoa. Lisboa: Educa, 1993. 